\title{
Statistical Analysis of the Relationship between Upper Tropospheric Cold Lows and Tropical Cyclone Genesis over the Western North Pacific
}

\author{
Hironori FUDEYASU \\ Yokohama National University, Yokohama, Japan \\ and \\ Ryuji YOSHIDA \\ CIRES, University of Colorado Boulder, Colorado, USA \\ NOAA Earth System Research Laboratory, Colorado, USA \\ RIKEN Center for Computational Science, Kobe, Japan \\ Research Center for Urban Safety and Security, Kobe University, Kobe, Japan
}

(Manuscript received 23 March 2018, in final form 24 December 2018)

\begin{abstract}
This study examined the statistical characteristics of tropical cyclones (TCs) for which the cyclogenesis (TCG) process was modulated by upper tropospheric cold lows (UCLs) over the western North Pacific during the 38 years from 1979 to 2016. Among the 965 TCs, 90 TCs (9\%, 2.4 per year) were defined as having TCG influenced by UCLs in the northwest quadrant of the TC region (UL-TCs). Most UL-TCs occurred in the summer, with large variability in the annual occurrence rate of UL-TCs during June to October, ranging from 0 to approximately $30 \%$. The annual variation was related to the activity of the Tibetan high and the summer temperature anomaly over Japan. The extremely hot summer of 2016 was partly enhanced by the intense Tibetan high, when 4 UL-TCs also occurred. The average location of UL-TCs at the time of TCG and tropical storm formation (TSF) was significantly farther to the north than the average location of TCs not formed under the influence of UCL (N-UL-TCs). Many UL-TCs occurred in lower tropospheric environments associated with the shear line or confluence regions. The UL-TCs tended to move northward, and the occurrence rate of UL-TCs that made landfall in Japan was approximately double that of other countries. The atmospheric environmental parameters around UL-TCs at the time of TCG were more favorable for the development of TCs than those around N-UL-TCs. In contrast, the atmospheric and oceanic environmental parameters around UL-TCs at the time of TSF were less favorable for the development of TCs, such that UL-TCs tended to remain at weak intensity.
\end{abstract}

Keywords tropical cyclone; genesis process; upper tropospheric cold lows

Citation Fudeyasu, H., and R. Yoshida, 2019: Statistical analysis of the relationship between upper tropospheric cold lows and tropical cyclone genesis over the western North Pacific. J. Meteor. Soc. Japan, 97, 439-451, doi: 10.2151/jmsj.2019-025.

Corresponding author: Hironori Fudeyasu, Faculty of Education, Yokohama National University, 79-2 Tokiwadai, Hodogaya-ku, Yokohama, 240-8501, Japan

E-mail: fude@ynu.ac.jp

J-stage Advance Published Date: 13 December 2018

(C) The Author(s) 2019. This is an open access article published by the Meteorological Society of Japan under a Creative Commons Attribution 4.0 International (CC BY 4.0) license (https://creativecommons.org/licenses/by/4.0). 


\section{Introduction}

Tropical cyclones (TCs) form under the large-scale environmental conditions favorable for cyclogenesis (TCG) (e.g., Gray 1968, 1998). The lower tropospheric flow patterns that contribute to TCG over the western North Pacific (WNP) can be grouped into five categories (Ritchie and Holland 1999): shear line (SL), confluence region (CR), monsoon gyre (GY), easterly wave (EW), and the Rossby wave energy dispersion from a preexisting TC (PTC).

The large-scale environmental conditions in the upper troposphere also strongly affect TCG over the WNP (e.g., Briegel and Frank 1997). Most previous studies of TCG associated with upper tropospheric forcing focused on tropical upper tropospheric troughs (TUTTs). Colon and Nightingale (1963) have reported that upper tropospheric southwesterlies on the eastern and southern sides of a TUTT provide favorable environmental conditions for the development of low-level disturbances. Sadler (1976) showed that a TUTT has three possible mechanisms for the development of TCs over the WNP: (1) the accompanying subequatorial ridge on the south side of a TUTT can decrease the vertical shear; (2) divergent flow on the southeast side of the cyclonic circulation (TUTT cell) in a TUTT can increase the ventilation aloft to aid development of TCs; and (3) channels to large-scale westerlies on the south side of a TUTT may be established for efficient outflow of released heat. Many previous statistical analyses (Briegel and Frank 1997; Ritchie and Holland 1999; Fu et al. 2007; Chen et al. 2008; Wang and $\mathrm{Wu} 2016$ ) demonstrated that the climatological features of the environmental conditions favorable for TCG coexisted with a TUTT over the WNP. Briegel and Frank (1997) analyzed 41 TCG cases in 1988 and 1989 and found that 25 TCs formed when a TUTT was present, and 16 TCs formed when a TUTT was located in the northwest region, within $2,500 \mathrm{~km}$ of the TCG location prior to the time of TCG.

Other previous studies (Japan Meteorological Agency 1990; McTaggart-Cowan et al. 2013) have proposed upper tropospheric cold lows (UCLs) as another possible upper tropospheric factor contributing to TCG over the WNP. UCLs are generally defined as a depression with a cold air center in the upper troposphere and are related to a cutoff low in either mid-latitude westerlies (Molinari and Vollaro 1989; Postel and Hitchman 1999; Sakamoto and Takahashi 2005) or a TUTT cell (Sadler 1976; McTaggart-Cowan et al. 2013). A cutoff low is recognized as a meso- $\alpha-$ scale-isolated low-pressure system that moves without merging with an upper tropospheric trough. A TUTT cell is a deep upper tropospheric trough that forms a low-pressure center. Here, following previous studies, UCLs refer to both cutoff lows and TUTT cells.

Japan Meteorological Agency (1990) reported that tropical depressions were well developed on the south and southeast sides of UCLs, where the convective instability was enhanced by the UCLs. The upper tropospheric divergence and weak vertical shear in the convective instability regions on the southeast side of UCLs appear to facilitate lower level lifting and convective development in the core regions of the TCs (Shi et al. 1990; Rappin et al. 2011; Sears and Velden 2014). It has been hypothesized that the upper tropospheric divergence and ascending motion associated with a UCL may help induce low-level mass and moisture convergence, which facilitate the generation of deep convection and the bottom-up growth mechanism of TCG (Kelly and Mock 1982; Hendricks et al. 2004; Montgomery et al. 2006). In a previous study by Nonaka (2005), a statistical analysis of 118 TCG events over the WNP from 1999 to 2003 found that TCG cases were associated with UCLs.

Another previous study by Wei et al. (2016) investigated changes in TC track and intensity due to UCLs over the WNP during the 13 years from 2000 to 2012. The results of this study showed that $73 \%$ of TCs coexisted with UCLs that included an upper tropospheric low originating from TUTT cells and cutoff lows in the mid-latitudes, and $44 \%$ of the TCs had interacted with UCLs during their lifetimes. A greater number of UCLs appeared in the western sectors of $\mathrm{TC}$ circulations within a $10^{\circ}$ radius. A previous study presented the global climatology of baroclinically influenced TC developments using an objective classification strategy. This study showed that a troughinduced environment during TC-development, which is generally associated with a TUTT cell, provided a relatively efficient pathway for TCG over the WNP and North Atlantic basins.

Although Wei et al. (2016) have revealed the statistical characteristics of TCs interacting with UCLs throughout the TC lifecycle, few have examined the characteristics of TCs where TCG was influenced by UCLs in the northwest quadrant of the TCG region (hereinafter referred to as UL-TCs). In addition, the analysis period of the statistical study described above was only 4 years, and annual changes in UL-TCs were not investigated. Thus, the objective of this study was to examine the annual and seasonal changes in UL-TCs over the WNP over a period of 38 years (1979-2016). In particular, during the summers of 2015 and 2016, 
there were several differences in the upper tropospheric environmental conditions that may have contributed to TCG. This study also investigated the statistical characteristics of UL-TCs over the WNP and the environmental conditions around them, including both atmospheric and oceanic physical parameters.

\section{Data and definition}

This study examined 965 TCs occurring over the WNP during the 38 years from 1979 to 2016 with tropical storm (TS) intensity or greater, i.e., a maximum sustained wind speed of at least 35 knots, as derived from the best-track data archives of the Regional Specialized Meteorological Center. Since the focus of this study was the early phase of the cyclogenesis process, the location of the first besttrack record for each TC was taken as the location of TCG. The location of TCG for each TC was generally identified from the tropical depression or low before TS intensity was reached. Following Yoshida and Ishikawa (2013), the time of TCG was defined as 69 hours prior to the time of the first best-track record for each TC.

As in several previous studies (e.g., Wei et al. 2016), UCLs were detected as strong cyclonic circulations at $200-\mathrm{hPa}$ height with a cold anomaly at $300-$ $\mathrm{hPa}$ height using global reanalysis data, namely the Japanese 55-year reanalysis project dataset (JRA55; Kobayashi et al. 2015) (details are available online at http://jra.kishou.go.jp/JRA-55/index_en.html). The JRA55 dataset contains 6-hourly data with a horizontal resolution of $1.25^{\circ}$ for both longitude and latitude, and data are available from 1958 to the present day. To detect UCLs, we computed the area-averaged 200-hPa height horizontal wind and $300-\mathrm{hPa}$ height temperature fields derived from JRA55 at the time of TCG. The target area in our study was the northwest quadrant within $1,500 \mathrm{~km}$ from the location of TCG at the time of TCG. The following quantitative definitions were used to detect UCLs that may have contributed to TCG:

(1) The UCL in the target area at the location closest to TCG had a relative vorticity greater than $5.0 \times$ $10^{-5} \mathrm{~s}^{-1}$ at $200 \mathrm{hPa}$.

(2) The divergence and north-south component of the horizontal wind above TCG $(200 \mathrm{hPa})$ were positive.

(3) The temperature of the UCL at $300 \mathrm{hPa}$ was lower than the average of the temperatures $3.75^{\circ}$ east and $5.0^{\circ}$ west of the UCL.

Although some previous studies (e.g., Wernli and Sprenger 2007; Wei et al. 2016) defined UCLs by cutoff lows only, some of the UCLs detected by our definitions were not cutoff lows. Upper tropospheric lows that did not have the typical structure of a UCL were removed by this subjective check. Figure 1 shows the general features of UCLs detected by the above definitions. UCLs decreased the vertical shear in the north-south direction and enhanced the upper tropospheric divergence on their southeastern side, which provides favorable environmental conditions for TCG.

This study compared the statistical characteristics of the environmental conditions around UL-TCs with those of TCs that had formed without UCLs (N-ULTCs). Atmospheric physical parameters were calculated from the JRA55, and oceanic physical parameters were derived from the three-dimensional variationalbased parent domain output from the 30-year fourdimensional variational ocean reanalysis dataset for the WNP (FORA-WNP30; Usui et al. 2017) (details are available online at http://synthesis.jamstec.go.jp/ FORA). It should be noted that the present study did not use the nested domain output of the FORA-WNP30 dataset with a horizontal resolution of $0.1^{\circ}$ because the nested domain was limited in its coverage of the study area from 1982 to 2015 . To compare the features of the environmental conditions around UL-TCs, we also investigated the environmental parameters around TCs whose TCG was influenced by UCLs in the northeast quadrant of the TCG region (hereafter referred to as NE-UL or NE-UL-TC), using the northeast quadrant within $1,500 \mathrm{~km}$ of the location of TCG and the above definitions, namely (1) and (3).

Using the JRA55 and FORA-WNP30, this study evaluated the following physical parameters: upper tropospheric divergence, lower tropospheric relative vorticity, magnitude of vertical shear, lower- and middle-tropospheric relative humidity, maximum potential intensity (MPI), convective available potential energy (CAPE) derived from the MPI equation, seasurface temperature (SST), tropical cyclone heat potential (TCHP), and depth of the $26^{\circ} \mathrm{C}$ oceanic isotherm. The relative humidity was calculated as the average over the height range of $850-700 \mathrm{hPa}$ (RHLO) and $500-300 \mathrm{hPa}$ (RHHI). The magnitude of the vertical shear was defined as the difference in horizontal wind between heights of 200 and $850 \mathrm{hPa}$ (SHRD), and between heights of 500 and $850 \mathrm{hPa}$ (SHRS). The $850-\mathrm{hPa}$ relative vorticity (VOR850) and the $200-\mathrm{hPa}$ divergence (DIV200) were also calculated. This study used two area averages: the average for the circular area with an $800-\mathrm{km}$ radius from the location of TCG, and an annulus of 200-800 km from the TC center. 
(a)

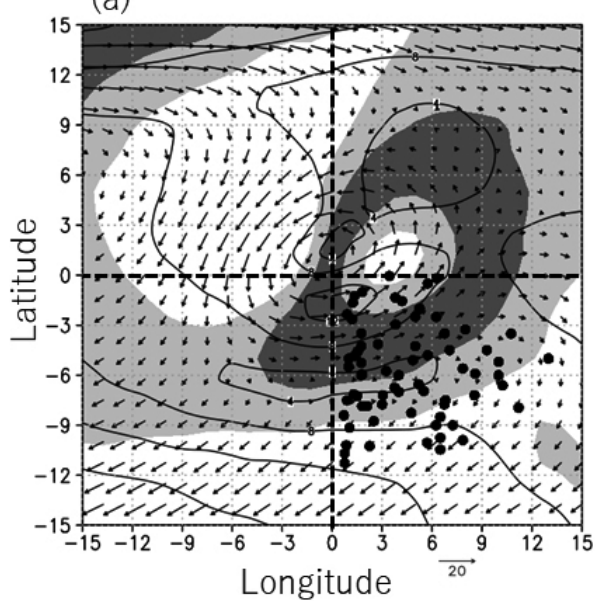

(b)

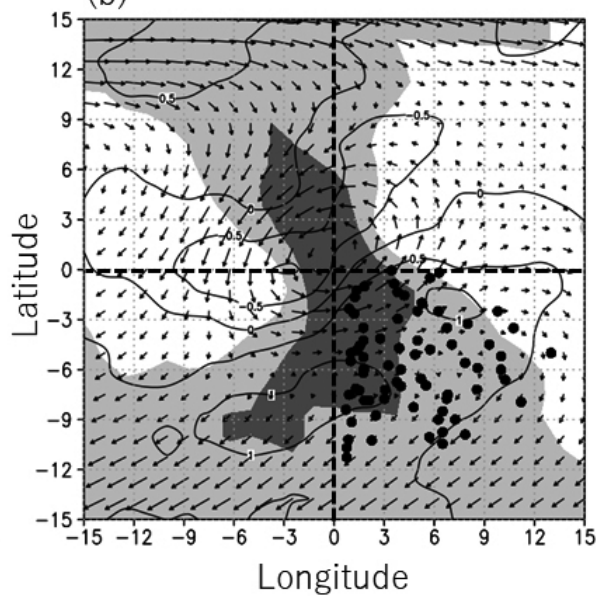

Fig. 1. Composites of 200-hPa horizontal winds $\left(\mathrm{m} \mathrm{s}^{-1}\right)$ : (a) vertical shear between 200 and $850 \mathrm{hPa}\left(\mathrm{m} \mathrm{s}^{-1}\right.$, contour) and vertical shear in the north-south direction ( $\mathrm{m} \mathrm{s}^{-1}$, shading), and (b) 200-hPa divergence $\left(\times 10^{-5} \mathrm{~s}^{-1}\right.$, contour) and divergence in the north-south direction $\left(\times 10^{-5} \mathrm{~s}^{-1}\right.$, shading). The composite was made with respect to 87 UCLs detected over the 38-year analysis period between June and October. The contour intervals are (a) $2 \mathrm{~m} \mathrm{~s}^{-1}$ and (b) $0.5 \times 10^{-5} \mathrm{~s}^{-1}$, respectively. The regions with (a) a vertical shear less than $4 \mathrm{~m} \mathrm{~s}^{-1}$ and (b) a divergence more than $0.8 \times 10^{-5} \mathrm{~s}^{-1}$ are heavily shaded, while the regions with (a) a vertical shear of 4-8 $\mathrm{m} \mathrm{s}^{-1}$ and (b) a divergence of $0.0-0.8 \times 10^{-5} \mathrm{~s}^{-1}$ are lightly shaded. The locations of UL-TCs relative to UCLs at the time of TCG are indicated by closed circles.

The former area average was applied to evaluate the atmospheric conditions during TCG, while the latter area average was applied after TS formation (TSF) to remove the TC structure, as in several previous studies (e.g., Knaff et al. 2005). Beneath the TC center, the oceanic physical parameters, SST, TCHP, and depth of the $26^{\circ} \mathrm{C}$ oceanic isotherm were evaluated to stratify distinct features. TCHP was estimated by summing the ocean heat content from the surface to the depth of the $26^{\circ} \mathrm{C}$ isotherm (Leipper and Volgenau 1972; Wada 2015).

This study examined the differences in MPI and CAPE between UL-TCs and N-UL-TCs using the atmospheric conditions derived from the JRA55 and the SST derived from the FORA-WNP30. The revised MPI equation presented in Bister and Emanuel (1998) was used in this study. To investigate atmospheric stability, this study used E-CAPE, a version of CAPE calculated from the simple equation presented in MPI theory, which is an approximate form.

This study also examined the relationships between UCLs and five relevant lower tropospheric flow patterns to TCG as identified by Ritchie and Holland (1999). To categorize the five TCG flow factors, we used the objective method developed by Yoshida and Ishikawa (2013) along with best-track data and the
JRA55. Details of the objective algorithm are provided in Yoshida and Ishikawa (2013) and Fudeyasu and Yoshida (2018).

\section{Results}

\subsection{Annual and seasonal variation in UL-TC}

Among the 965 TCs, 90 UL-TCs and 875 N-ULTCs were detected using our definitions. The occurrence rate of UL-TCs ( $9 \%$ ) was very small, similar to the results of Nonaka (2005) and McTaggart-Cowan (2013). Nonaka (2005) detected 4 TCs associated with a UCL, out of a total of 118 TCs (occurrence rate of $3 \%$ ), while McTaggart-Cowan et al. (2013) reported an average of 2.3 trough-induced TC developments per year over the WNP.

Among all the TCs, 672 TCs did not meet definition (1). In other words, a positive relative vorticity within $1,500 \mathrm{~km}$ of the northwest quadrant at the time of TCG was seen in only 293 TCs. Of these 293 TCs, 179 TCs were excluded since neither the southerlies nor the divergence at a height of $200 \mathrm{hPa}$ occurred above the TCG location. Of the remaining 114 TCs, 24 did not exhibit a distinct cold core in the upper troposphere.

Figure 2 shows the total number of UL-TCs for each month of the analysis period, and the rates of 


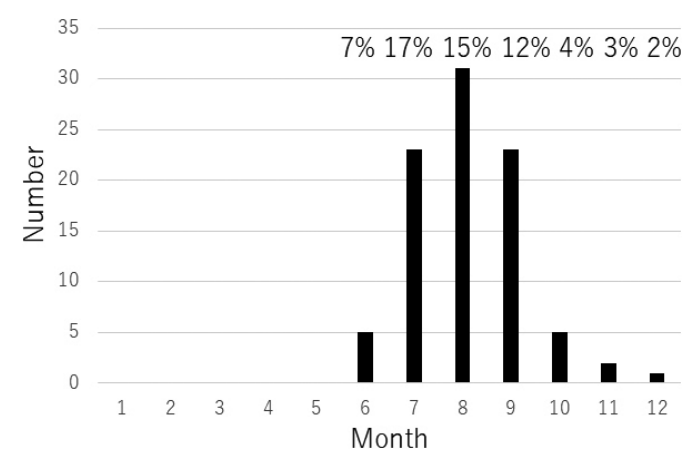

Fig. 2. Monthly total number of UL-TCs over the 38-year analysis period. The percentages are the rates of UL-TC occurrence divided by the monthly total of TCs.

UL-TC occurrence divided by the monthly total of TCs. There was large seasonal variability in the number of UL-TCs; most occurred in the summer, while only a few occurred in the winter. It should be noted that no UL-TCs occurred from January to May. The seasonality of UL-TCs is consistent with the results of Nonaka (2005) and McTaggart-Cowan (2013).

Figure 3 shows the annual number of UL-TCs and their rate of occurrence over the WNP from 1979 to 2016. The average was 2.4 per year, with 1992, 1999 , and 2001 experiencing 5 UL-TCs each, which was the highest number among all the years, followed by $1979,1982,1983,1984,1988,1990,2004,2009$, 2012, and 2016 with 4 UL-TCs each. In contrast, no UL-TCs occurred in 1995, 1997, 2003, and 2015. As shown in Fig. 3b, the occurrence rate of UL-TCs, i.e., the number of UL-TCs divided by the number of TCs from June to October, varied widely from 0 to approximately $30 \%$.

This study examined changes in the annual variability of UL-TCs related to the El Niño Southern Oscillation (ENSO), based on the JMA definition (details are available online at http://www.data.jma.go.jp/ gmd/cpd/db/elnino/learning/faq/elnino_table.html). The average annual number (2.6) of UL-TCs and their occurrence rate $(12 \%)$ in La Niña years were almost the same as in El Niño years $(2.2,9 \%)$ and neutral years (i.e., when neither phenomenon occurred) (2.4, $9 \%$ ). Therefore, the annual variability in UL-TCs was not related to the ENSO.

It is interesting to note that the annual variability in UL-TCs was related to the temperature anomaly during summer over Japan, resulting from the midtropospheric geopotential height in the mid-latitudes. Figure $4 \mathrm{a}$ shows a scatter plot of the number of UL-TCs and the temperature anomaly over Japan averaged from July to September, as provided by the JMA. The number of UL-TCs tended to increase with the temperature anomaly, where regression analysis yielded a correlation coefficient of 0.32 . Figure $4 \mathrm{~b}$ shows the composite of the $500-\mathrm{hPa}$ geopotential height averaged for the 8 years in which the July to September Japan temperature anomaly was more than $0.7^{\circ} \mathrm{C}(1994,1999,2000,2004,2010,2012,2013$, and 2016) as well as the difference in the $500-\mathrm{hPa}$ geopotential height between these 8 years and other years. The positive regions of this difference extended from the Asian continent to the sea east of Japan. A possible reason for the correlation between the annual variability in UL-TCs and the temperature anomaly over Japan is that the mid-tropospheric geopotential height over the northwestern part of the WNP is partly (a)

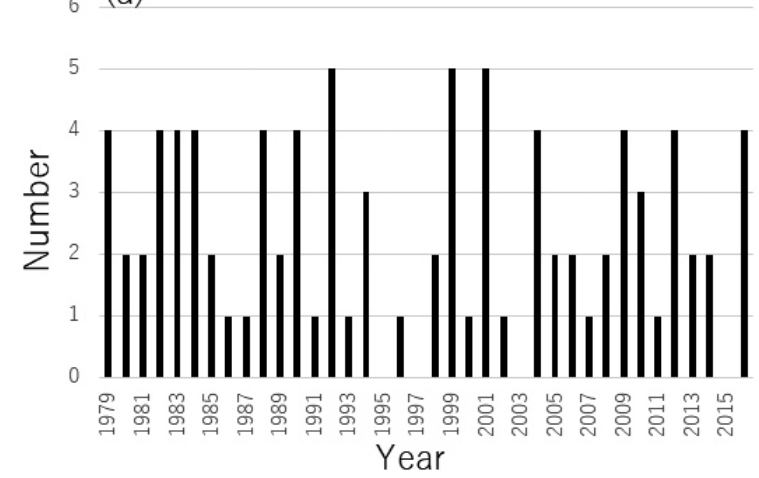

(b)

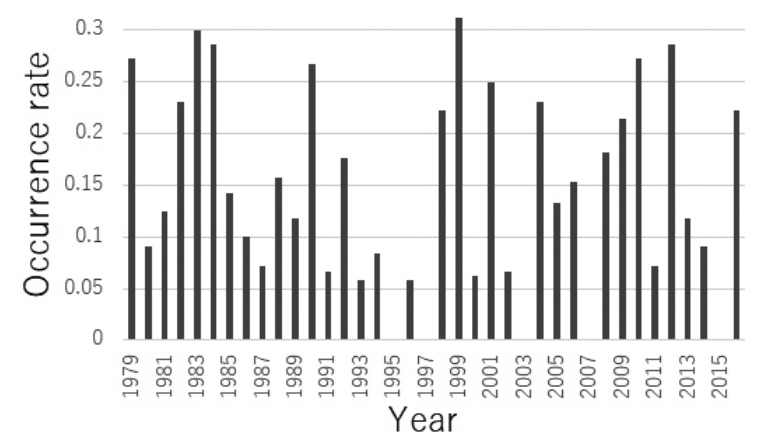

Fig. 3. Annual variation in (a) UL-TC occurrence over the 38-year analysis period and (b) occurrence rate of ULTCs normalized by the total number of TCs from June to October. 
(a)

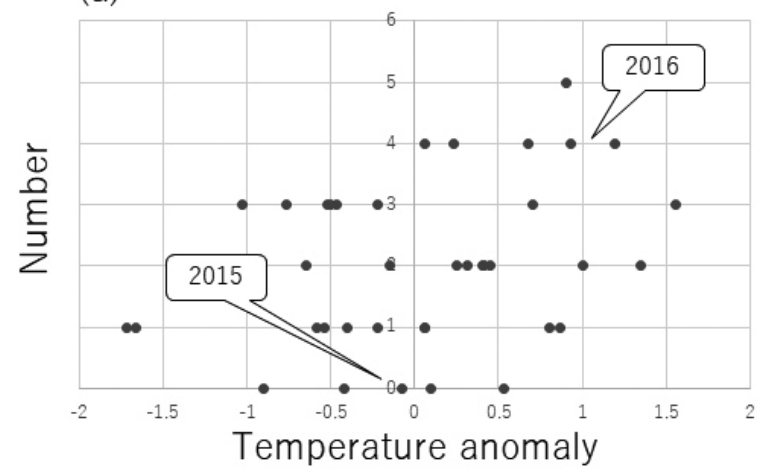

(b)

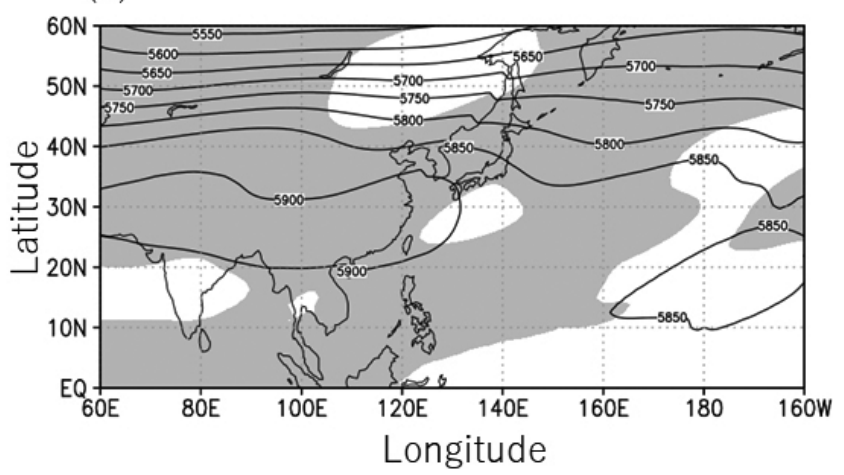

Fig. 4. (a) Scatter plot of the number of UL-TCs against the temperature anomaly over Japan from July to September. (b) The 500-hPa geopotential height (contour) averaged for the 8 years during which the temperature anomaly over Japan was more than $0.7^{\circ} \mathrm{C}(1994,1999,2000,2004,2010,2012,2013$, and 2016), and the difference in the $500-\mathrm{hPa}$ geopotential height between these 8 years and the other years (shading). The contour interval is $50 \mathrm{~m}$, while regions greater than $0 \mathrm{~m}$ are shaded.

enhanced by an upper tropospheric high, namely the Tibetan high. The UCLs frequently moved southwestward from the mid-latitudes when the anticyclonic circulation associated with the Tibetan high extended eastward and acted as a steering flow, leading to hotter summers over Japan. In fact, the extremely hot summer of 2016 was partly enhanced by the intense Tibetan high, when 4 UL-TCs also occurred. In most of the UL-TC cases, a UCL originating from cutoff lows in the mid-latitudes moved around the intense Tibetan high.

\subsection{Statistical characteristics of UL-TCS}

As discussed in the previous section, there was large seasonal variability in the occurrence of UL-TCs. To compare the statistical characteristics of UL-TCs and N-UL-TCs, this study considered the 743 TCs in the summer and autumn seasons (June to October), when both UL-TCs and N-UL-TCs can occur. A total of 87 UL-TCs $(12 \%)$ and 656 N-UL-TCs were detected during this analysis period.

Table 1 shows the average locations (namely, the climatological mean locations) of UL-TCs, N-ULTCs, and all TCs between June and October over the 38-year analysis period. Differences in the structure and environmental parameters between UL-TCs and N-UL-TCs were assessed using a $t$-test. The ratios in Table 1 were obtained by normalizing each variable, by subtracting the sample mean and dividing by the standard deviation. The average location of TCG was farther to the north for UL-TCs compared with
N-UL-TCs, and this difference was significant at the $5 \%$ level. Figure 5 shows the locations of UL-TCs and of the UCLs influencing TCG. The locations of the UCLs were concentrated at latitudes near $20^{\circ} \mathrm{N}$. The UL-TCs appeared in the zonal area farther to the north than the average location of N-UL-TCs and the climatological mean. Figure 5b shows the geographical location of UCLs with respect to the location of TCG; the distance between UCLs and TCG locations ranged from 133 to $1,450 \mathrm{~km}$, with an average of 883 $\mathrm{km}$, and all were located in the northwest quadrant of the TCG region.

As the location of UL-TCs at the time of TCG was usually farther north than the climatological mean, the location of UL-TCs at TSF and maturity (mature time) tended to be in the northern part of the WNP (Table 1). The time of TSF was defined as that when the minimum TS intensity threshold ( 35 knots) was reached, while the mature time was defined as the time when the maximum wind speed occurred. It should be noted that the average duration between TCG and TSF was significantly shorter for UL-TCs than for N-ULTCs. Although the time of TCG, i.e., the time of the first best-track record for each TC, depends on the limitations of the dataset (temporal resolution and observational capabilities), the statistical characteristics of UL-TCs that have a shorter duration between TCG and TS compared with the climatological mean are important for the prediction of TCs.

This study also calculated two other durations, i.e., the duration of the TC developmental stage (from the 
Table 1. Statistical summary of the characteristics of UL-TCs and N-UL-TCs, and the climatological mean for all TCs (ALL), between June and October over the 38-year analysis period. Areas for which a $t$-test indicated statistical differences with a $5 \%$ level of significance (10\% for maximum wind) are presented in bold, italic font. The percentages correspond to normalized variables, obtained by subtracting the sample mean and dividing by the sample standard deviation.

\begin{tabular}{|c|c|c|c|c|}
\hline & & UL-TC & N-UL-TC & ALL \\
\hline \multirow{3}{*}{ Time of TCG } & Number & 87 & 656 & 743 \\
\hline & Ave. lon. $\left({ }^{\circ} \mathrm{E}\right)$ & $140.5(9 \%)$ & $138.9(-1 \%)$ & 139.2 \\
\hline & Ave. lat. $\left({ }^{\circ} \mathrm{N}\right)$ & $16.8(28 \%)$ & $15.2(-4 \%)$ & 15.4 \\
\hline \multirow{3}{*}{ Time of TSF } & Ave. lon. $\left({ }^{\circ} \mathrm{E}\right)$ & $137.8(15 \%)$ & $135.3(-2 \%)$ & 135.6 \\
\hline & Ave. lat. $\left({ }^{\circ} \mathrm{N}\right)$ & $19.2(30 \%)$ & $17.4(-4 \%)$ & 17.7 \\
\hline & Duration from TCG (day) & $5.4(-20 \%)$ & $5.8(3 \%)$ & 5.8 \\
\hline \multirow{2}{*}{ One day after time of TSF } & $\Delta$ lon. $\left(^{\circ}\right)$ & $-1.7(13 \%)$ & $-2.2(-2 \%)$ & -2.2 \\
\hline & $\Delta$ lat. $\left(^{\circ}\right)$ & $2.3(25 \%)$ & $1.8(-3 \%)$ & 1.9 \\
\hline \multirow{5}{*}{ Mature time } & Ave. lon. $\left({ }^{\circ} \mathrm{E}\right)$ & $131.3(14 \%)$ & $128.9(-2 \%)$ & 129.2 \\
\hline & Ave. lat. $\left({ }^{\circ} \mathrm{N}\right)$ & $25.3(22 \%)$ & $23.7(-3 \%)$ & 23.9 \\
\hline & Duration from TSF (day) & $3.0(-7 \%)$ & $3.2(1 \%)$ & 3.2 \\
\hline & Maximum wind (knot) & $66.2(-13 \%)$ & $69.7(2 \%)$ & 69.3 \\
\hline & Minimum pressure $(\mathrm{hPa})$ & $967.6(16 \%)$ & $962.7(-2 \%)$ & 963.3 \\
\hline Decaying time & Duration from TSF (day) & $5.2(-6 \%)$ & $5.4(1 \%)$ & 5.4 \\
\hline
\end{tabular}
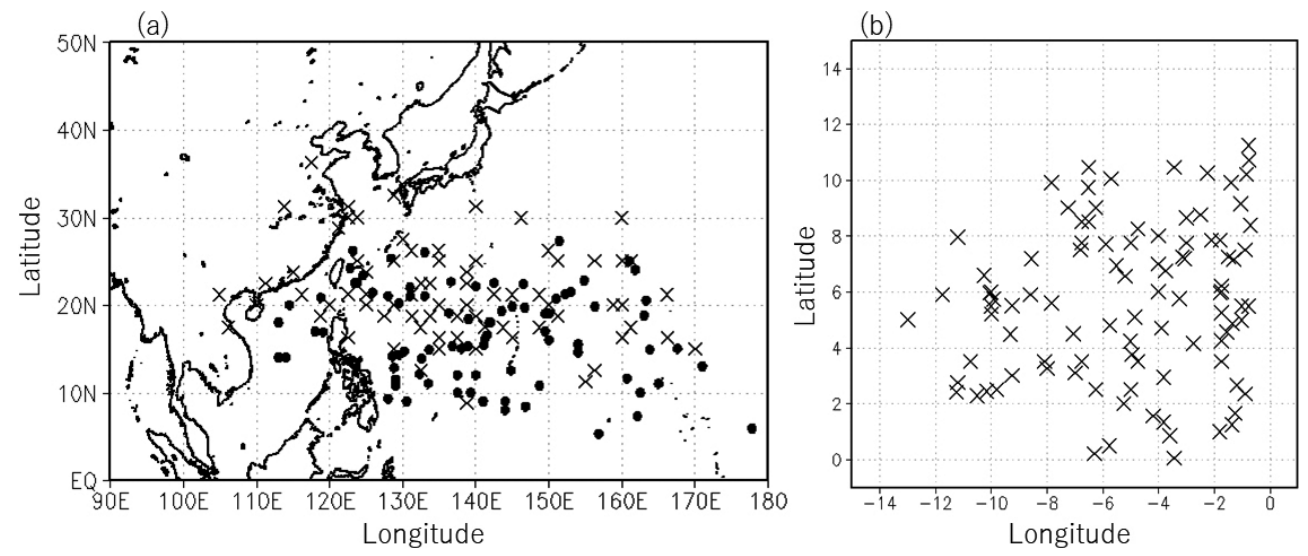

Fig. 5. Locations of (a) UL-TCs (closed circles) and UCLs (crosses), and (b) UCLs relative to UL-TCs at the time of TCG, over the 38-year analysis period.

TSF time to the mature time) and the lifetime of the TC (from the TSF time to the decay time) (Table 1). The decay time was defined as the point at which the system fell below the TS intensity threshold. Neither of these durations differed significantly between ULTCs and N-UL-TCs.

The statistical characteristics of the UL-TC movements were also investigated. The direction of movement at the time of TSF was defined in terms of the change in location of the TC from the time of TSF to the following day. The UL-TCs tended to move farther north than the N-UL-TCs (Table 1). Since it is possible that environmental flows influenced not only TCG but also the direction of movement of TCs, the upper-level southerlies associated with UCLs (Fig. 1) may have enhanced the northward movement of the UL-TCs after TSF.

Along the locations of each TC track, the number of landfalls for different countries in the WNP (Japan, China, Vietnam, and the Philippines) was determined. In this study, we defined a TC landfall when a TC track intersected with a coastline (Fudeyasu et al. 


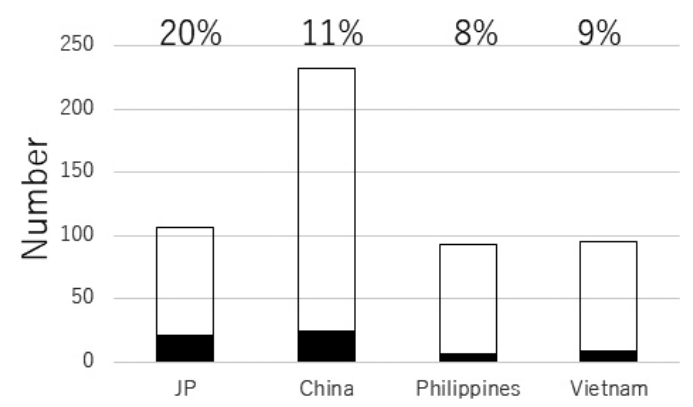

Fig. 6. Number of TCs that made landfall in Japan, China, the Philippines, and Vietnam between June and October over the 38-year analysis period. The filled bars indicate UL-TCs, while the percentages correspond to the UL-TC occurrence rates divided by the total number of TCs that made landfall in each country.

2014). Over the 38-year study period, a total of 107 TCs resulted in landfalls in Japan between June and October (Fig. 6). Among these, UL-TCs were the most frequent, with 21 landfalls and an occurrence rate (i.e., the number of UL-TC landfalls divided by the total number of TC landfalls) of $20 \%$. The occurrence rate of UL-TC landfalls in Japan was approximately double that of other countries.

At the mature time, there were significant differences in average intensity among the different cyclone types (Table 1): the minimum central pressure of the UL-TCs was significantly higher than that of the $\mathrm{N}-$-UL-TCs at the $5 \%$ significance level, while the maximum wind speed of the UL-TCs was significantly lower than that of the N-UL-TCs at the $10 \%$ significance level. This study also examined the occurrence of different TC intensity categories based on the Saffir-Simpson scale (Simpson 1974). The rates of occurrence, stratified by class and divided by the total number of occurrences for UL-TCs, N-UL-TCs, and all TCs, are shown in Fig. 7. The occurrence rate of the TS class for UL-TCs was about $50 \%$, which is higher than that for N-UL-TCs (45\%) and the climatological mean (45\%). By contrast, the occurrence rate for major TCs exceeding category 3 on the SaffirSimpson scale (> 96 knots) was $10 \%$ for UL-TCs, which is lower than that for the climatological mean $(15 \%)$ and N-UL-TCs $(15 \%)$. This means that the UL-TCs tended to remain at weak intensity, rarely developing into intense TCs.

\subsection{Environmental parameters around UL-TCS}

Tables 2 and 3 show the atmospheric and oceanic

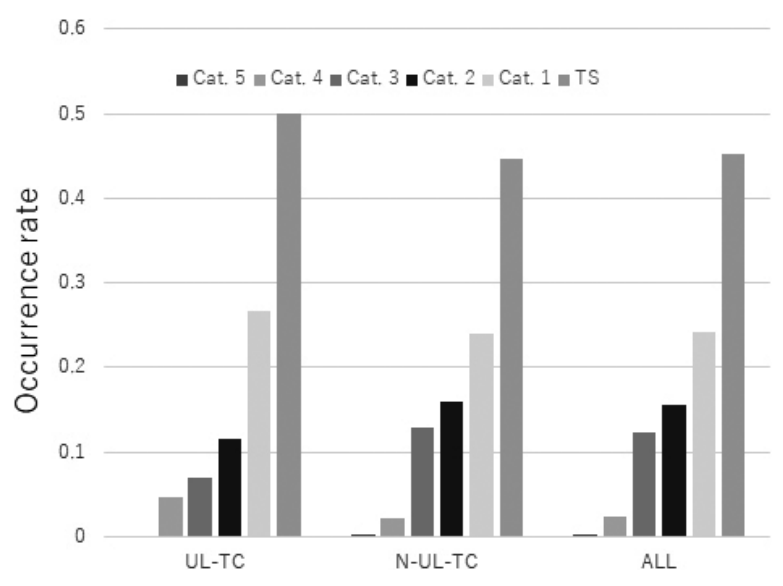

Fig. 7. Occurrence rate by $\mathrm{TC}$ intensity class divided by the number of UL-TC, N-UL-TC, and all TC occurrences between June and October over the 38-year analysis period. Classes are defined by the TS and Saffir-Simpson scales.

physical parameters for UL-TCs, N-UL-TCs, and all TCs, at the time of TCG and TSF. It should be noted that the oceanic physical parameters, namely E-CAPE and MPI, were calculated over 34 years from 1982 to 2015 , which corresponds to the period of available FORA-WNP30.

At the time of TCG, in addition to the higher DIV200 around UL-TCs than that around N-ULTCs, there were significant differences in some of the other atmospheric physical parameters. The SHRS around UL-TCs was significantly weaker than that around N-UL-TCs, while the RHLO and RHHI around UL-TCs were significantly higher at the $5 \%$ significance level. This means that the atmospheric environment around UL-TCs at the time of TCG was more favorable for TCG than that around N-UL-TCs, which is consistent with the results of previous studies (e.g., Japan Meteorological Agency 1990) reporting that UCLs may help induce moisture convergence, facilitating the generation of deep convection and thus favoring TCG. However, it should be noted that the VOR850, E-CAPE, MPI, and oceanic physical parameters (Table 3) at the time of TCG did not differ between UL-TCs and N-UL-TCs.

Regarding the atmospheric physical parameters at the time of TSF, the relative humidity and vertical shear did not differ between UL-TCs and N-UL-TCs, but the DIV200, VOR850, E-CAPE, and MPI around UL-TCs were significantly lower than those around N-UL-TCs. There were also significant differences in the oceanic physical parameters; the SST, TCHP, and 
Table 2. As in Table 1, for the atmospheric environmental parameters between June and October during the 38-year analysis period. The E-CAPE and MPI were evaluated over the 34 years from 1982 to 2015, for which FORAWNP30 were available.

\begin{tabular}{|c|c|c|c|c|}
\hline & & UL & N-UL & ALL \\
\hline \multirow{8}{*}{ Time of TCG } & RHLO (\%) & $71.5(31 \%)$ & $70.3(-3 \%)$ & 70.5 \\
\hline & RHHI (\%) & $44.0(38 \%)$ & $40.6(-4 \%)$ & 41.0 \\
\hline & $\operatorname{VOR} 850\left(\times 10^{-5} \mathrm{~s}^{-1}\right)$ & $4.1(2 \%)$ & $4.0(0 \%)$ & 4.0 \\
\hline & $\operatorname{DIV} 200\left(\times 10^{-5} \mathrm{~s}^{-1}\right)$ & $4.6(42 \%)$ & $2.9(-5 \%)$ & 3.1 \\
\hline & $\operatorname{SHRS}\left(\mathrm{m} \mathrm{s}^{-1}\right)$ & $3.1(-27 \%)$ & $3.8(2 \%)$ & 3.7 \\
\hline & $\operatorname{SHRD}\left(\mathrm{m} \mathrm{s}^{-1}\right)$ & $8.7(-12 \%)$ & $9.6(1 \%)$ & 9.5 \\
\hline & E-CAPE $\left(\mathrm{J} \mathrm{kg}^{-1}\right)$ & $14281.1(0 \%)$ & $14278.2(-0 \%)$ & 14278.5 \\
\hline & MPI maximum wind $\left(\mathrm{m} \mathrm{s}^{-1}\right)$ & $120.8(0 \%)$ & $120.8(0 \%)$ & 120.8 \\
\hline \multirow{8}{*}{ TS formation time (TSF) } & RHLO (\%) & $72.2(-7 \%)$ & $72.4(0 \%)$ & 72.4 \\
\hline & RHHI (\%) & $45.4(-4 \%)$ & $45.8(1 \%)$ & 45.8 \\
\hline & $\operatorname{VOR} 850\left(\times 10^{-5} \mathrm{~s}^{-1}\right)$ & $8.9(-21 \%)$ & $11.0(3 \%)$ & 10.8 \\
\hline & $\operatorname{DIV} 200\left(\times 10^{-5} \mathrm{~s}^{-1}\right)$ & $6.5(-21 \%)$ & $7.4(3 \%)$ & 7.3 \\
\hline & SHRS $\left(\mathrm{m} \mathrm{s}^{-1}\right)$ & $3.1(5 \%)$ & $3.0(-1 \%)$ & 3.0 \\
\hline & $\operatorname{SHRD}\left(\mathrm{m} \mathrm{s}^{-1}\right)$ & $7.1(1 \%)$ & $7.0(-0 \%)$ & 7.1 \\
\hline & E-CAPE $\left(\mathrm{J} \mathrm{kg}^{-1}\right)$ & $13950.6(-17 \%)$ & $14398.0(3 \%)$ & 14348.0 \\
\hline & MPI maximum wind $\left(\mathrm{m} \mathrm{s}^{-1}\right)$ & $119.0(-18 \%)$ & $121.1(3 \%)$ & 120.8 \\
\hline
\end{tabular}

Table 3. As in Tables 1 and 2, for the oceanic physical parameters below the TC center between June and October during the 34-year analysis period from 1982 to 2015, for which FORAWNP30 were available.

\begin{tabular}{|c|c|c|c|c|}
\hline & & $\mathbf{U L}$ & N-UL & ALL \\
\hline \multirow{3}{*}{ Time of TCG } & $\operatorname{SST}\left({ }^{\circ} \mathrm{C}\right)$ & $29.3(6 \%)$ & $29.3(-1 \%)$ & 29.3 \\
\hline & TCHP $\left(\mathrm{kJ} \mathrm{cm}^{-2}\right)$ & $94.9(-8 \%)$ & $98.3(1 \%)$ & 97.9 \\
\hline & $26-{ }^{\circ} \mathrm{C}-\operatorname{depth}(\mathrm{m})$ & $92.9(-13 \%)$ & $99.8(2 \%)$ & 99.0 \\
\hline \multirow{3}{*}{ TS formation time (TSF) } & $\mathrm{SST}\left({ }^{\circ} \mathrm{C}\right)$ & $28.9(-14 \%)$ & $29.1(3 \%)$ & 29.1 \\
\hline & TCHP $\left(\mathrm{kJ} \mathrm{cm}^{-2}\right)$ & $77.4(-15 \%)$ & $84.5(2 \%)$ & 83.7 \\
\hline & $26-{ }^{\circ} \mathrm{C}$-depth (m) & $80.2(-23 \%)$ & $91.3(3 \%)$ & 90.0 \\
\hline
\end{tabular}

depth of the $26^{\circ} \mathrm{C}$ isotherm for UL-TCs were smaller than those for N-UL-TCs at the $5 \%$ significance level. Therefore, the TC-development efficiency of the atmospheric and oceanic environments around UL-TCs was lower than that around N-UL-TCs at the time of TSF. This seems to be due to the average location of UL-TCs at the time of TSF being farther north. The lower efficiency of these atmospheric and oceanic conditions means that the UL-TCs tend to remain at weak intensity. There were significant differences in the atmospheric and oceanic physical parameters between the mature and decay times (not shown).

To compare the features of the environmental parameters around UL-TCs, Tables 4 and 5 show the physical parameters for NE-UL-TCs, i.e., those influenced by UCLs in the northeast quadrant of the TCG region. Over the 38-year analysis period, there were 743 TCs between June and October, of which 79 were classified as NE-UL-TCs. At the time of both TCG and TSF, most of the physical atmospheric parameters did not differ between NE-UL-TCs and TC environments without northeastern UCLs (N-NE-ULs or N-NE-ULTCs), with the exception of E-CAPE and MPI. The E-CAPE and MPI around NE-UL-TCs were lower than those around N-NE-UL-TCs. In terms of oceanic physical parameters, the SST (TCHP) of NE-UL-TCs was smaller than that of N-NE-UL-TCs at the time of TCG (TSF) at the $5 \%$ significance level. Therefore, the TC-development efficiency of the atmospheric and oceanic environments around NE-UL-TCs was lower than that around N-NE-UL-TCs, in contrast to the environments around UL-TCs at the time of TCG. 
Table 4. As in Table 2, for the atmospheric environmental parameters around NE-UL and N-NE-UL between June and October during the 38-year analysis period.

\begin{tabular}{|c|c|c|c|c|}
\hline & & NE-UL & N-NE-UL & ALL \\
\hline \multirow{8}{*}{ Time of TCG } & RHLO (\%) & $70.0(-14 \%)$ & $70.5(2 \%)$ & 70.5 \\
\hline & RHHI (\%) & $41.5(6 \%)$ & $41.0(-1 \%)$ & 41.0 \\
\hline & $\operatorname{VOR} 850\left(\times 10^{-5} \mathrm{~s}^{-1}\right)$ & $4.6(9 \%)$ & $3.9(-1 \%)$ & 4.0 \\
\hline & DIV200 $\left(\times 10^{-5} \mathrm{~s}^{-1}\right)$ & $3.4(9 \%)$ & $3.1(-0 \%)$ & 3.1 \\
\hline & SHRS $\left(\mathrm{m} \mathrm{s}^{-1}\right)$ & $3.6(-2 \%)$ & $3.7(0 \%)$ & 3.7 \\
\hline & $\operatorname{SHRD}\left(\mathrm{m} \mathrm{s}^{-1}\right)$ & $9.1(-8 \%)$ & $9.6(1 \%)$ & 9.5 \\
\hline & E-CAPE $\left(\mathrm{J} \mathrm{kg}^{-1}\right)$ & $13003.4(-23 \%)$ & $13464.2(3 \%)$ & 13417.5 \\
\hline & MPI maximum wind $\left(\mathrm{m} \mathrm{s}^{-1}\right)$ & $114.7(-23 \%)$ & $116.7(2 \%)$ & 116.5 \\
\hline \multirow{8}{*}{ TS formation time (TSF) } & RHLO (\%) & $72.6(6 \%)$ & $72.3(-0 \%)$ & 72.4 \\
\hline & RHHI (\%) & $45.2(-6 \%)$ & $45.8(1 \%)$ & 45.8 \\
\hline & $\operatorname{VOR} 850\left(\times 10^{-5} \mathrm{~s}^{-1}\right)$ & $12.0(16 \%)$ & $10.6(-1 \%)$ & 10.8 \\
\hline & DIV200 $\left(\times 10^{-5} \mathrm{~s}^{-1}\right)$ & $7.5(4 \%)$ & $7.3(-1 \%)$ & 7.3 \\
\hline & $\operatorname{SHRS}\left(\mathrm{m} \mathrm{s}^{-1}\right)$ & $3.2(10 \%)$ & $2.9(-1 \%)$ & 3.0 \\
\hline & $\operatorname{SHRD}\left(\mathrm{m} \mathrm{s}^{-1}\right)$ & $7.2(3 \%)$ & $7.0(-0 \%)$ & 7.1 \\
\hline & E-CAPE $\left(\mathrm{J} \mathrm{kg}^{-1}\right)$ & $13973.2(-17 \%)$ & $14308.0(2 \%)$ & 14271.0 \\
\hline & MPI maximum wind $\left(\mathrm{m} \mathrm{s}^{-1}\right)$ & $119.2(-17 \%)$ & $120.7(2 \%)$ & 120.5 \\
\hline
\end{tabular}

Table 5. As in Table 3, for the oceanic environmental physical parameters around NE-UL and N-NE-UL during the 38-year analysis period between June and October.

\begin{tabular}{llccc}
\hline & & NE-UL & N-NE-UL & ALL \\
\hline \multirow{3}{*}{ Time of TCG } & SST $\left({ }^{\circ} \mathrm{C}\right)$ & $\mathbf{2 9 . 2}(-18 \%)$ & $\mathbf{2 9 . 3}(2 \%)$ & $\mathbf{2 9 . 3}$ \\
& $\mathrm{TCHP}\left(\mathrm{kJ} \mathrm{cm}^{-2}\right)$ & $92.2(-14 \%)$ & $98.4(2 \%)$ & 97.7 \\
& $26-{ }^{\circ} \mathrm{C}-\mathrm{depth}(\mathrm{m})$ & $97.4(-4 \%)$ & $99.3(0 \%)$ & 99.1 \\
\hline \multirow{3}{*}{ TS formation time $(\mathrm{TSF})$} & $\mathrm{SST}\left({ }^{\circ} \mathrm{C}\right)$ & $29.1(-1 \%)$ & $29.1(0 \%)$ & 29.1 \\
& $\mathrm{TCHP}\left(\mathrm{kJ} \mathrm{cm}{ }^{-2}\right)$ & $\mathbf{7 6 . 0}(-23 \%)$ & $\mathbf{8 4 . 6}(3 \%)$ & 83.7 \\
& $26-{ }^{\circ} \mathrm{C}-\mathrm{depth}(\mathrm{m})$ & $80.8(-13 \%)$ & $90.8(1 \%)$ & 90.0 \\
\hline
\end{tabular}

\subsection{Lower tropospheric flows contributing to TCGs around UL-TCS}

This study examined the relationship between UL-TCs and the lower tropospheric environmental flows contributing to TCG classified in Ritchie and Holland (1999), namely the TCG factors SL, CR, GY, EW, and PTC. When the major TCG factor could not be determined using the objective detection method developed in Yoshida and Ishikawa (2013), it was denoted as unclassified flow (UCF). Figure 8 shows the distribution of TCG factors among 90 UL-TCs over the 38-year study period. Of the 90 UL-TCs, those related to the SL and CR were the most frequent (28 UL-TCs), followed by those related to the EW (12 UL-TCs) and then to the GY (10 UL-TCs). Our results are consistent with those of Ritchie and Holland (1999), in which it was found that for the many TCG cases influenced by a UCL, a CR was also present in the lower tropospheric environment.
As shown in Fig. 9, there was a large difference in the number of TCs related to the five TCG factors. To compare the effects of the different environments on UL-TC formation, the rate of UL-TC occurrence was divided by the number of TCs for each TCG factor, shown as percentages in Fig. 9. The occurrence rate of the UL-TCs was similar among the TCG factors, with the exception of UCF and CR. The occurrence rate of UL-TCs related to the CR (15\%) was larger than those for the other known TCG factors.

Fudeyasu and Yoshida (2018) revealed the statistical characteristics of TCs stratified by TCG factors. The occurrence rate of TCs that made landfall in Japan was highest for the CR, followed by SL. Figure 10 shows the tracks of 28 TCs that formed in an environment associated with both SL and a UCL (SL-UL-TC), and both CR and a UCL (CR-UL-TC). Of the 28 SLUL-TCs, 7 TCs made landfall in Japan, corresponding to an occurrence rate of $25 \%$. On the other hand, 10 


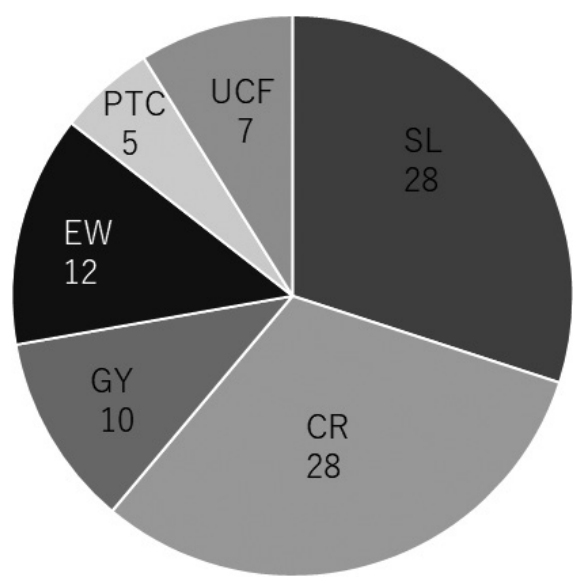

Fig. 8. Distribution of UL-TCs stratified by TCG factors over the 38-year analysis period. Note: shear line, SL; confluence region, CR; monsoon gyre, GY; easterly wave, EW; Rossby wave energy dispersion, PTC; unclassified flow, UCF.

CR-UL-TCs made landfall in Japan, corresponding to an occurrence rate of $36 \%$. Although the number of TCs that made landfall is not sufficient to perform a robust statistical analysis, the trends in the movement of CR-UL-TCs and SL-UL-TCs are important for disaster prevention in Japan.

It should be noted that 7 of the 40 UCF-TCs were UL-TCs. This means that 7 TCs were formed in an environment with upper tropospheric forcing but

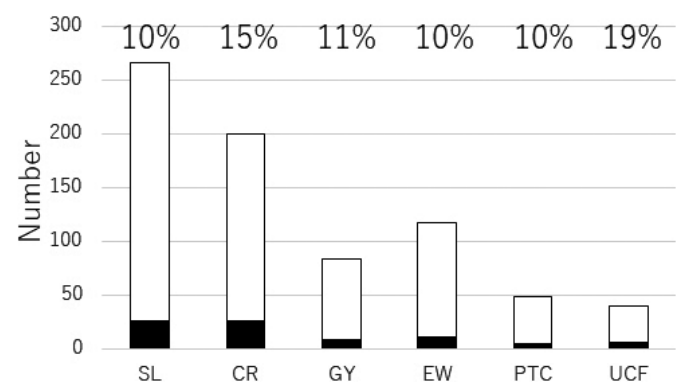

Fig. 9. Number of TCs and UL-TCs stratified by TCG factors over the 38-year analysis period. The filled bars indicate UL-TCs, and the percentages are the UL-TC occurrence rates divided by the total number of TCs for each of the TCG factors.

without lower tropospheric forcing. No clear evidence of upper tropospheric forcing having a direct impact on TCG was found. This means that a UCL provides favorable environmental conditions for the development of low-level disturbances on its southeastern side, but it is not directly responsible for the low-level disturbances. Because the purpose of this study was to investigate the characteristics of TCs affected by a UCL, clarification of the impact of upper tropospheric forcing on TCG is reserved for future studies.

\section{Conclusion}

This study statistically examined the characteristics of TCs for which TCG was modulated by UCLs over
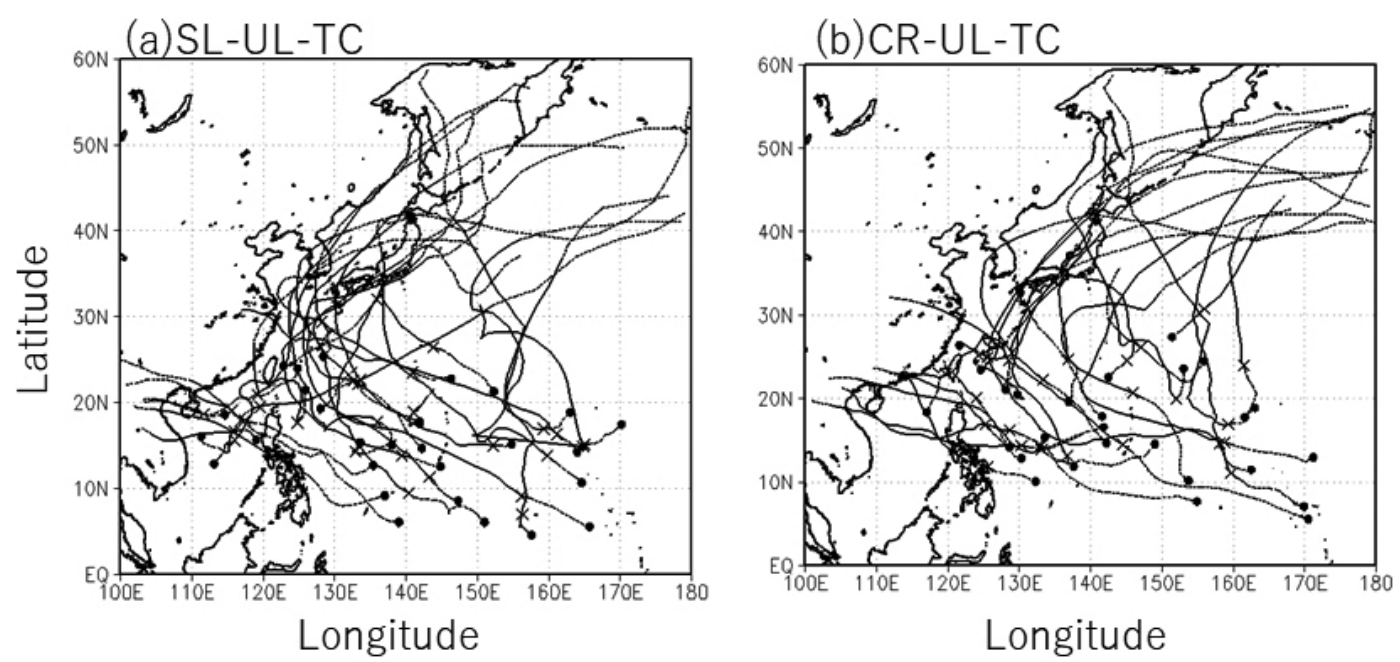

Fig. 10. TC tracks (lines), and locations at TCG (closed circle) and TSF (crosses) of (a) 28 SL-UL-TCs and (b) 28 CR-UL-TCs. The dashed lines correspond to tracks of TCs below TS intensity. 
the WNP, during the 38 years from 1979 to 2016. Among the 965 TCs, 90 TCs $(9 \%, 2.4$ per year) were defined as having UCL contributions to TCG (ULTCs). Regarding the geographical locations of the UCLs with respect to the locations of TCG, the distance between the location of a UCL and TCG ranged from 133 to $1,450 \mathrm{~km}$, with an average distance of 883 $\mathrm{km}$, where the UCLs were situated to the northwest of the location of TCG. Analysis of the seasonal changes in TCG cases influenced by UCLs showed that most UL-TCs occurred in the summer. The annual variation in the occurrence rate of UL-TCs during June to October exhibited substantial variability, ranging from 0 to approximately $30 \%$. The annual variation in UL-TCs was related to the activity of the Tibetan high and the summer temperature anomaly over Japan. The extremely hot summer of 2016, during which four UL-TCs occurred, was enhanced by the Tibetan high.

The statistical characteristics of UL-TCs and the environmental parameters around them, including both atmospheric and oceanic features, were revealed. Our results, comparing the characteristics of UL-TCs and N-UL-TCs between June and October over the 38-year analysis period, are summarized below:

- The average location of UL-TCs at the time of TCG was farther north than that of N-UL-TCs.

- The average duration from TCG to TSF was significantly shorter for UL-TCs than for N-UL-TCs.

- The UL-TCs tended to move northward at the time of TSF.

- The occurrence rate of UL-TCs that made landfall in Japan was approximately double that in other countries.

- UL-TCs tended to remain at weak intensity and rarely developed into intense TCs.

- At the time of TCG, the lower- and middletropospheric relative humidity around UL-TCs was higher, and the vertical shear around UL-TCs was weaker, in comparison to N-UL-TCs. The atmospheric environment around UL-TCs was more favorable for the development of TCs than that around N-UL-TCs. However, the E-CAPE, MPI, and oceanic physical parameters did not differ between UL-TCs and N-UL-TCs.

- At the time of TSF, the relative humidity and vertical shear did not differ between UL-TCs and N-UL-TCs, but the upper tropospheric divergence, lower tropospheric relative vorticity, E-CAPE, MPI, SST, TCHP, and depth of the $26^{\circ} \mathrm{C}$ isotherm around UL-TCs were lower than those around N-UL-TCs. The atmospheric and oceanic environments around UL-TCs were less suitable for the development of
TCs than those around N-UL-TCs.

- At the mature time, there were significant differences in the atmospheric and oceanic physical parameters between UL-TCs and N-UL-TCs.

- Many UL-TCs in lower tropospheric environments were associated with the SL or CR.

- The TCs that formed in an environment associated with both the CR and a UCL (CR-UL-TCs) tended to move northward, resulting in a higher occurrence rate of landfalls in Japan.

The direct impact of upper tropospheric forcing from UCLs on TCG remains unclear. However, the relationship between UCLs that influenced TCG and the statistical characteristics of TCs shown here can be used in future cyclogenesis studies. In addition, the statistical characteristics of UL-TCs are important for the prediction of TCG; in particular, understanding the tendency for UL-TCs to move northward will be important for disaster prevention in Japan.

\section{Acknowledgments}

The authors would like to thank Dr. A. Wada for his helpful support of data analysis. This study utilized the dataset of JRA55 provided by the JMA. This study also utilized the dataset of FORA-WNP30, which was kindly provided by the Japan Agency for MarineScience and Technology (JAMSTEC) and the Meteorological Research Institute of Japan Meteorological Agency (JMA/MRI). This work was supported by the Ministry of Education, Culture, Sports, Science and Technology (MEXT) KAKENHI Grants 17H02956 and 17K14398. Joint Usage/Collaborative Research Center for Multidisciplinary Disaster Prevention Study of the Disaster Prevention Research Institute (DPRI) at Kyoto University (29G-05), Collaborative Research Project on Computer Science with High-Performance Computing at Nagoya University (2017). This research was also supported by the Integrated Research Program for Advancing Climate Models (TOUGOU program) from the MEXT, Japan.

\section{References}

Bister, M., and K. A. Emanuel, 1998: Dissipative heating and hurricane intensity. Meteorol. Atmos. Phys., 65, 233-240.

Briegel, L. M., and W. M. Frank, 1997: Large-scale influences on tropical cyclogenesis in the western North Pacific. Mon. Wea. Rev., 125, 1397-1413.

Chen, T.-C., S.-Y. Wang, M.-C. Yen, and A. J. Clark, 2008: Are tropical cyclones less effectively formed by easterly waves in the western North Pacific than in the North Atlantic? Mon. Wea. Rev., 136, 4527-4540. 
Colón, J. A., and W. R. Nightingale, 1963: Development of tropical cyclones in relation to circulation patterns at the 200-millibar level. Mon. Wea. Rev., 91, 329-336.

Fu, B., T. Li, M. S. Peng, and F. Weng, 2007: Analysis of tropical cyclogenesis in the western North Pacific for 2000 and 2001. Wea. Forecasting, 22, 763-780.

Fudeyasu, H., and R. Yoshida, 2018: Western North Pacific tropical cyclone characteristics stratified by genesis environment. Mon. Wea. Rev., 146, 435-446.

Fudeyasu, H., S. Hirose, H. Yoshioka, R. Kumazawa, and S. Yamasaki, 2014: A global view of the landfall characteristics of tropical cyclones. Trop. Cyclone Res. Rev., 3, 178-192.

Gray, W. M., 1968: Global view of the origin of tropical disturbances and storms. Mon. Wea. Rev., 96, 669-700.

Gray, W. M., 1998: The formation of tropical cyclones. Meteorol. Atmos. Phys., 67, 37-69.

Hendricks, E. A., M. T. Montgomery, and C. A. Davis, 2004: The role of vortical hot towers in the formation of Tropical Cyclone Diana (1984). J. Atmos. Sci., 61, 1209-1232.

Japan Meteorological Agency, 1990: Manual of the operational forecasting of tropical cyclones. $150 \mathrm{pp}$ (in Japanese).

Kelly, W., Jr., and D. R. Mock, 1982: A diagnostic study of upper tropospheric cold lows over the western North Pacific. Mon. Wea. Rev., 110, 471-480.

Knaff, J., C. Sampson, and M. DeMaria, 2005: An operational statistical typhoon intensity prediction scheme for the western North Pacific. Wea. Forecasting, 20, 688-688.

Kobayashi, S., Y. Ota, Y. Harada, A. Ebita, M. Moriya, H. Onoda, K. Onogi, H. Kamahori, C. Kobayashi, H. Endo, K. Miyaoka, and K. Takahashi, 2015: The JRA55 Reanalysis: General specifications and basic characteristics. J. Meteor. Soc. Japan, 93, 5-48.

Leipper, D. F., and L. D. Volgenau, 1972: Hurricane heat potential of the Gulf of Mexico. J. Phys. Oceanogr., 2, 218-224.

McTaggart-Cowan, R., T. J. Galarneau, Jr., L. F. Bosart, R. W. Moore, and O. Martius, 2013: A global climatology of baroclinically influenced tropical cyclogenesis. Mon. Wea. Rev., 141, 1963-1989.

Molinari, J., and D. Vollaro, 1989: External influences on hurricane intensity. Part I: Outflow layer eddy angular momentum fluxes. J. Atmos. Sci., 46, 1093-1105.

Montgomery, M. T., M. E. Nicholls, T. A. Cram, and A. B. Saunders, 2006: A vortical hot tower route to tropical cyclogenesis. J. Atmos. Sci., 63, 355-386.

Nonaka, N., 2005: Characteristics of the developmental sequence of Typhoons in the Northwest Pacific Ocean.
Meteorological Satellite Center Technical Note, 46, 15-32 (in Japanese).

Postel, G. A., and M. H. Hitchman, 1999: A climatology of Rossby wave breaking along the subtropical tropopause. J. Atmos. Sci., 56, 359-373.

Rappin, E. D., M. C. Morgan, and G. J. Tripoli, 2011: The impact of outflow environment on tropical cyclone intensification and structure. J. Atmos. Sci., 68, 177194.

Ritchie, E. A., and G. J. Holland, 1999: Large-scale patterns associated with tropical cyclogenesis in the western Pacific. Mon. Wea. Rev., 127, 2027-2043.

Sadler, J. C., 1976: A role of the tropical upper tropospheric trough in early season typhoon development. Mon. Wea. Rev., 104, 1266-1278.

Sakamoto, K., and M. Takahashi, 2005: Cut off and weakening processes of an upper cold low. J. Meteor. Soc. Japan, 83, 817-834.

Sears, J., and C. S. Velden, 2014: Investigating the role of the upper-levels in tropical cyclone genesis. Trop. Cyclone Res. Rev., 3, 91-110.

Shi, J.-J., S. W.-J. Chang, and S. Raman, 1990: A numerical study of the outflow layer of tropical cyclones. Mon. Wea. Rev., 118, 2042-2055.

Simpson, R. H., 1974: The hurricane disaster-potential scale. Weatherwise, 27, 169-186.

Usui, N., T. Wakamatsu, Y. Tanaka, N. Hirose, T. Toyoda, S. Nishikawa, Y. Fujii, Y. Takatsuki, H. Igarashi, H. Nishikawa, Y. Ishikawa, T. Kuragano, and M. Kamachi, 2017: Four-dimensional variational ocean reanalysis: A 30-year high-resolution dataset in the western North Pacific (FORA-WNP30). J. Oceanogr., 73, 205-233.

Wada, A. 2015: Verification of tropical cyclone heat potential for tropical cyclone intensity forecasting in the western North Pacific. J. Oceanogr., 71, 373-387.

Wang, C., and L. Wu, 2016: Interannual shift of the tropical upper-tropospheric trough and its influence on tropical cyclone formation over the western North Pacific. $J$. Climate, 29, 4203-4211.

Wei, N., Y. Li, D.-L. Zhang, Z. Mai, and S.-Q. Yang, 2016: A statistical analysis of the relationship between upper-tropospheric cold low and tropical cyclone track and intensity change over the western North Pacific. Mon. Wea. Rev., 144, 1805-1822.

Wernli, H., and M. Sprenger, 2007: Identification and ERA15 climatology of potential vorticity streamers and cutoffs near the extratropical tropopause. J. Atmos. Sci., 64, 1569-1586.

Yoshida, R., and H. Ishikawa, 2013: Environmental factors contributing to tropical cyclone genesis over the western North Pacific. Mon. Wea. Rev., 141, 451-467. 